\title{
PENERAPAN PRODUKSI RAMAH LINGKUNGAN PADA PROSES PRODUKSI UKM BATIK TULIS
}

\author{
Ong Andre Wahyu Riyanto ${ }^{1}$, Subaderi², Ahmad Sholikhul Nafi ${ }^{3}$ \\ ${ }^{1}$ Universitas Wijaya Putra \\ ${ }^{2}$ Universitas Wijaya Putra \\ ${ }^{3}$ Universitas Wijaya Putra \\ ongandre@uwp.ac.id, subaderi@uwp.ac.id
}

\begin{abstract}
Abstrak
Banyak UKM Batik yang telah berkembang di kota Kabupaten Sidoarjo, Jawa Timur, diindikasikan sebagai penyebab pencemaran lingkungan yang terjadi akibat penggunaan bahan kimia dalam proses produksi batik. Proses produksi batik tulis mayoritas menggunakan pewarna kimia yang tergolong pada kategori tidak sustain (tidak ramah lingkungan) tetapi affordable (layak secara ekonomis). Untuk meningkatkan tingkat eko-efisiensi bisa dilakukan dengan cara menaikkan harga jual, mengurangi biaya produksi atau menciptakan produksi bersih yang bisa dilakukan dengan menggunakan bahan pewarna alternatif (pewarna alami) dan menerapkan strategi end of life melalui: 1)Penerapan teknologi tepat guna pencelupan kain batik pada proses pewarnaan. 2)Konversi bahan bakar menggunakan tabung LPG $3 \mathrm{~kg}$. 3)Pembuatan kowen sederhana. 4) Penerapan instalasi pengolahan air limbah (IPAL) dengan teknologi elektrokoagulan. Hasil kegiatan ini adalah alternatif teknologi yang paling layak diterapkan pada UKM batik Tulis Desa Jetis di Kabupaten Sidoarjo Sidoarjo yaitu penerapan teknologi tepat guna pencelupan kain batik pada proses pewarnaan. Dengan penerapan teknologi tepat guna pencelupan kain batik pada proses pewarnaan akan mampu meningkatkan eko-efesiensi pada proses produksi UKM batik Tulis Desa Jetis Sidoarjo.
\end{abstract}

Kata Kunci : Batik, UKM, teknologi tepat guna, produksi bersih, eko-efesiensi

\section{PENDAHULUAN}

Indonesia merupakan bagian dari negara berkembang di Asia Tenggara sangatlah membutuhkan sektor usaha menengah dan kecil mandiri (UMKM) sebagai salah satu sektor penggerak perekonomian nasional (Puspitasari dkk). Menurut Irjayanti dan Azis (2012) dalam persaingan ekonomi secara global, dari 100 bisnis di Indonesia 99\% diantaranya adalah UMKM yang pertumbuhannya relatif stabil.

Sayangnya produk UMKM batik di Indonesia mengalami tingkat kompetisi yang ketat dengan produk tekstil impor, bahkan di negara Indonesia sendiri (Riyanto dkk, 2018).

Dalam perdagangan bebas pasar Indonesia telah dibanjiri oleh produk-produk impor dimana pelanggan leluasa memilih dan menyesuaikan produk. Kesepakatan perdagangan bebas Asean AFTA, ACFTA sampai MEA telah berdampak signifikan terhadap pertumbuhan ekonomi UMKM di Indonesia, termasuk UMKM produksi kain batik (Nurhayati, S., 2016).

Negara-negara yang kinerja ekonominya sebagian besar ditopang oleh UMKM telah

$$
\text { Teknologi Tepat Guna }
$$


mengimplementasikan berbagai strategi untuk meningkatkan daya saing UKM mereka (Destari, \& Harjanti, 2018).

Upaya terbaik yang dapat dilakukan oleh UMKM untuk bertahan dalam persaingan ekonomi global adalah melalui peningkatan produktivitas. Demikian pula yang perlu dilakukan oleh sentra UKM Batik Tulis di Desa Jetis Kabupaten Sidoarjo. Peningkatan produksi kain batik pada sektor UMKM akan berdampak pada permasalahan lingkungan. Sentra produksi batik di kampung Batik Jetis Sidoarjo berpotensi menghasilkan limbah cair yang cukup tinggi dengan volume sebesar $+/-568$ $\mathrm{m}^{3}$ per hari dengan hasil produksi kurang lebih 1400 potong kain batik per hari (Suhartini dkk, 2011).

Tujuan kegiatan pengabdian ini adalah mengurangi aktivitas non-produktif dan waste serta mengurangi dampak limbah produksi terhadap lingkungan sekitar. Sebuah metode yang sesuai untuk membantu UMKM Batik Tulis di Desa Jetis

Kabupaten Sidoarjo agar mampu meningkatkan produktivitas sekaligus menurunkan dampak lingkungan adalah penerapan metode Produksi Ramah Lingkungan melalui perancangan teknologi tepat guna untuk proses produksi.

\section{METODE}

Di Kampung Batik Jetis terdapat 20 pengrajin batik yang bertempat tinggal sekaligus menjalankan usaha kerajinan dan penjualan di lokasi ini. Kegiatan ini dilaksanakan di Batik Tulis Namiroh, Batik Tulis Dahlia, dan Batik Tulis Azizah. Kegiatan produksi masih tradisional belum menggunakan bantuan peralatan/mesin teknologi tepat guna. UMKM Kampung Batik Jetis belum menerapkan unit pengolahan limbah serta limbah produksi dibuang langsung ke sungai di lingkungan sekitar tempat tinggal.

Dalam penerapan produksi ramah lingkungan, pertama menentukan jenis-jenis pemborosan air, energi, bahan baku, dan aditif pada proses produksi batik. Kedua, menentukan keseimbangan proses pembuatan batik tradisional di lantai produksi. Permasalahan: potongan kain perca yang tidak terpakai. Akar penyebab: a) tidak akurat dalam pemotongan kain mori. b)akurasi dan disiplin pekerja. Usulan Perbaikan: menggunakan kembali potongan kain mori sebagai kerajinan tangan, seperti serbet, saputangan dan pernak-pernik lainnya. Permasalahan: air limbah. Akar penyebab: penggunaan air dalam jumlah besar dalam proses pembuatan batik tradisional. Usulan Perbaikan: a) mengatur pengoperasian proses pencelupan, misalnya pertama-tama lakukan proses pencelupan untuk warna yang lebih cerah lalu lakukan proses pencelupan untuk warna yang lebih gelap. b) Memisahkan antara air limbah konsentrat dan air limbah. c)pemasangan unit Pengolahan Air Limbah

Pada proses pemotongan bahan mori, terjadi kerusakan bahan karena cara menyimpan yang tidak baik. Bahan mori menjadi sobek atau kotor. Pada UKM, cara penyimpanan kain diletakkan di lantai (gambar 1).

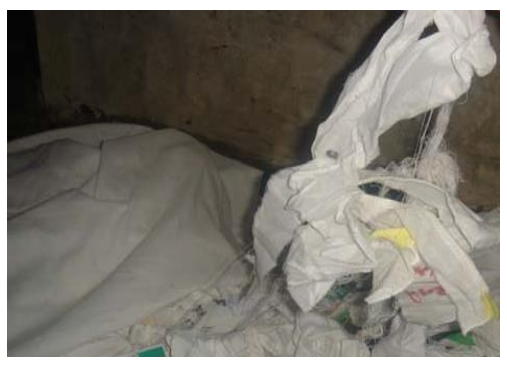

Gambar 1. Kain mori bahan batik

Pemborosan juga terjadi pada pemakaian malam. Sisa malam pada proses mbatik menempel pada alat canting, atau berceceran di lantai sekitar tempat bekerja. Pada proses nembok, sisa malam menempel pada peralatan canting, wajan, pengaduk, penampung ceceran malam/karung dan lantai sekitar tempat kerja. Pemborosan pemakaian malam juga terjadi pada proses lorod. Malam yang mencair pada proses lorod menempel pada drum dan pengaduk atau larut terbuang bersama air sisa lorod. dalam jumlah yang cukup besar.

Kebutuhan air pada proses colet untuk mencairkan zat warna. Kebutuhan air untuk proses colet per hari hanya sekitar dua liter per hari. Sedangkan proses celup dan lorod memerlukan air paling banyak. Proses ini memerlukan banyak air untuk pewarnaan, perendaman dan pencucian kain

$$
\text { Teknologi Tepat Guna }
$$


batik. Air bekas mencuci dan merendam dibuang dan tidak dimanfaatkan karena mengandung banyak zat pewarna serta zat tambahan lain.

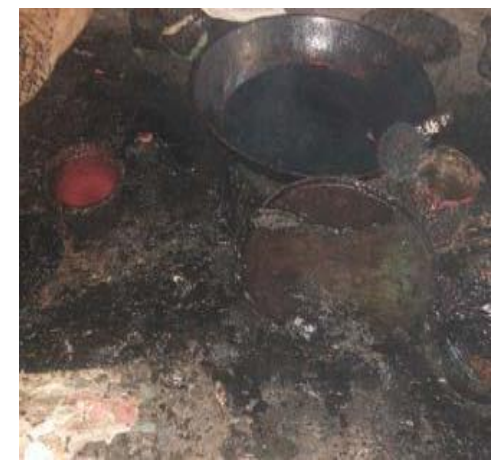

Gambar 2. NPO malam pada proses nembok

Air bekas ini sebenarnya masih bisa dimanfaatkan apabila diolah lebih lanjut. Sisa air perendaman dan pencucian setelah proses pewarnaan dan lorod dapat dilihat pada Gambar 3.

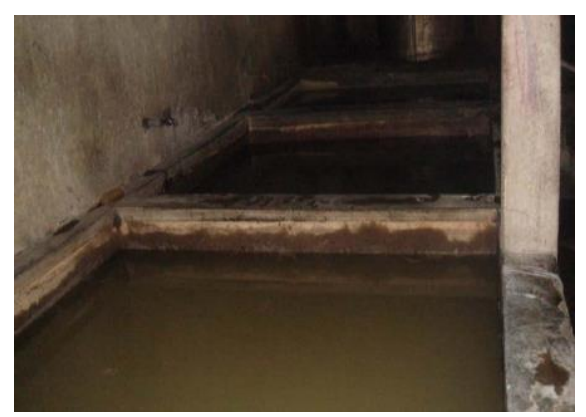

Gambar 3. NPO sisa air perendaman dan pencucian

Untuk mengetahui besar pemborosan yang terjadi dan besar limbah yang dihasilkan oleh masing- masing UKM selama satu tahun produksi, perlu dihitung besar output yang dihasilkan dan input yang diperlukan selama satu tahun produksi. Jumlah hari produksi dalam satu tahun dihitung berdasarkan jumlah hari kerja seminggu dengan 12 hari libur nasional. Jumlah 6 hari kerja seminggu dan 12 hari libur nasional, maka jumlah hari produksi setahun sama dengan 6 x 52 minggu - 12
$=300$ hari produksi. Rata-rata jumlah hari produksi per bulan 300 hari : $12=25$ hari.

Output produksi selama satu tahun produksi dihitung berdasarkan perkiraan masing-masing UKM. Batik Tulis Namiroh menyatakan bahwa output produksi sebulan sebanyak lebih kurang 20.162 meter atau setara dengan 241.944 meter dalam satu tahun proses produksi. Sedangkan Batik Tulis Dahlia menyatakan bahwa output produksi rata- rata sebulan adalah 9.000 meter atau 108.000 meter dalam satu tahun produksi. Selanjutnya Batik Tulis Azizah memperkirakan bahwa output produksi selama sebulan 1.600 meter atau setara dengan 19.200 meter selama satu tahun produksi.

Berdasarkan data output produksi satu tahun, maka dihitung kebutuhan bahan baku dan penolong, energy dan air selama satu tahun produksi. Perhitungannya adalah kebutuhan bahan baku dan penolong, energy dan air per meter output produksi dikalikan output produksi selama satu bulan/satu tahun produksi akan dihasilkan kebutuhan bahan baku dan penolong, energy dan air selama satu bulan/satu tahun produksi.

Non Product Output (NPO) yang berasal dari penggunaan bahan baku dan penolong, energy dan air diperkirakan berdasarkan observasi adalah sebagai berikut:

1. Sisa kain perca berbeda-berbeda pada masingmasing perusahaan. Kain perca pada Batik Tulis Namiroh antara $15-35 \mathrm{~cm}$ per hari atau diambil nilai tengah $25 \mathrm{~cm}$ per hari. Sedangkan pada Batik Tulis Dahlia lebih kurang $60 \mathrm{~cm}$ per hari dan pada Batik Tulis Azizah $10 \mathrm{~cm}$ perhari.

2. Malam yang hilang diperkirakan berdasarkan pengalaman masing-masing UMKM antara $50 \%-70 \%$. Untuk perhitungan malam yang hilang digunakan nilai konservatif $60 \%$.

3. Minyak tanah yang hilang akibat proses pengisian kompor yang tidak hati-hati. Perkiraan setiap pengisian kompor jumlah minyak tanah yang menetes ke lantai sebanyak $4 \mathrm{ml}$ per kompor. Pengisian kompor biasa dilakukan tiap hari. Maka jumlah minyak tanah yang hilang selama sehari dihitung dengan cara $4 \mathrm{ml}$ kali 
jumlah kompor yang dimiliki masing-masing UKM.

4. Berdasarkan proses analisa laboratorium terhadap sampel limbah larutan sisa pewarnaan pada proses celup, diperoleh berat kering Zat warna. Dari setiap 1 liter larutan sisa pencelupan pada masing-masing perusahaan diperoleh sebanyak 13 gram pada perusahaan Batik Tulis Namiroh, Batik Tulis Dahlia 1,65 gram, dan 2 gram pada perusahaan Batik Tulis Azizah.

5. Limbah cair sisa pewarnaan pada setiap UKM berbeda. Untuk Batik Tulis Namiroh sebanyak 16 liter dalam satu kali celup, dimana dalam satu hari 4 kali pencelupan. Pada perusahaan Batik Tulis Dahlia sisa cairan pewarnaan sebanyak 2 liter dalam satu kali pencelupan, sedangkan dalam 1 hari dilakukan 2 kali pencelupan. Sisa cairan pewarna pada perusahaan Batik Tulis Azizah sebanyak 7 liter dalam satu kali celup, dan dalam 1 hari dilakukan 4 kali celup.

6. Air yang hilang berbentuk limbah cair sebanyak air yang digunakan dalam proses produksi celup dan lorod. Biaya kehilangan air sebesar biaya retribusi air ditambah dengan biaya pengolahan limbah yang menjadi beban lingkungan.

7. Sebagai akibat air sisa produksi yang tidak dipergunakan kembali untuk proses produksi, maka kesempatan untuk mendapatkan penghematan listrik menjadi hilang.

\section{Pengukuran Tingkat Eko-efisiensi Menggunakan Life Cycle Assessment (LCA)}

Pada tahapan ini dilaksanakan pengukuran besar dampak dari proses pembuatan batik tulis. Perhitungan ini dipakai untuk mengolah data dan kaitannya dengan aspek lingkungan. perhitungan LCA ini terbagi menjadi tiga fase, yaitu:

1. Sasaran dan lingkup LCA produk. Tujuan fase ini untuk menentukan tujuan, sistem yang akan dievaluasi, batasan-batasan, dan asumsi-asumsi yang berhubungan dengan dampak di sepanjang siklus hidup dari sistem yang sedang dievaluasi untuk pembuatan produk batik.

2.Perhitungan life cycle inventory (LCI) produk. Untuk fase kedua adalah fase life cycle inventory (LCI) dimana dalam perhitungan LCI ini menunjukkan kebutuhan material yang digunakan dalam satuan berat dan sumber energi listrik yang dipakai serta flow prosesnya.

3.Perhitungan life cycle impact assessment (LCIA) produk. Life cycle impact assessment (LCIA) adalah fase ke tiga atau tahap analisa mengenai jenis dan besarnya nilai tiap kategori dampak yang dihasilkan.

Pada fase ini pengolahan dilakukan dengan metode eco-costs 2007, nilai dan indikator dari ecocosts ini adalah sesuai standar dari World Business Council for Sustainable Development. Pada fase LCIA ini terbagi lagi menjadi beberapa tahapan yaitu karakterisasi, normalisasi, pembobotan, dan single score dari dampak lingkungan yang dihasilkan. Dari keempat tahapan analisis ini menghasilkan nilai eco-cost dari masing- masing produk.

\section{Net Value Product}

Net value ini diperoleh dengan mengurangi keuntungan dengan biaya produksi yang diperoleh dengan menggunakan metode harga pokok proses, sehingga besarnya nilai dari net value ini dipengaruhi oleh biaya-biaya yang dibutuhkan dalam produksi suatu produk dan nilai penjualan dari produk tersebut. Input dari net value ini antara lain biaya-biaya yang terkait dalam proses produksi serta benefit dari produk batik. Perhitungan net value dapat dilihat pada persamaan (1) berikut ini:

Net Value = Harga Jual-Biaya Produksi (1)

\section{HASIL DAN PEMBAHASAN}

Eko-efisiensi dalam proses produksi ramah lingkungan merupakan strategi menggabungkan konsep efisiensi ekonomi berdasarkan prinsip efisiensi pemakaian sumber daya alam. Oleh karena itu jika ingin meningkatkan eko efisiensi pada batik tulis pewarna kimia pelaku industri batik harus menerapkan produksi bersih/ramah lingkungan sehingga eco-cost nya semakin rendah. Alternatif

$$
\text { Teknologi Tepat Guna }
$$


strategi yang dapat dipakai untuk menciptakan produksi bersih adalah dengan menggunakan pewarna alternatif (pewarna alami) dan menerapkan strategi End of Life (EoL).

Strategi End of Life yang digunakan adalah perancangan teknologi tepat guna pencelupan kain batik pada proses pewarnaan proses pencelupan kain menjadi lebih ergonomis dan cepat. Perancangan teknologi tepat guna pencelupan kain batik pada proses pewarnaan tersebut untuk meningkatkan eko-efisiensi dari proses produksi batik agar dapat meminimalisir NPO yang terbuang berupa limbah cair dan padat. Manfaat dari teknologi tepat guna pencelupan kain batik pada proses pewarnaan ini adalah mewujudkan produksi bersih yang ramah lingkungan.

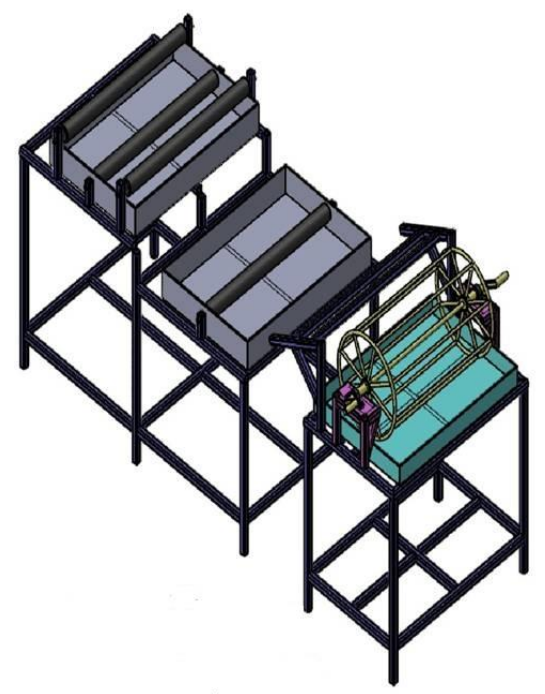

Gambar 4. Teknologi tepat guna pencelupan kain batik pada proses pewarnaan

\section{KESIMPULAN}

Berdasarkan hasil perhitungan Life Cycle Assessment, eco-cost untuk produk batik tulis pewarna kimia adalah sebesar Rp 500.000,- dengan tingkat eko efisiensi sebesar $69,20 \%$. Batik tulis pewarna kimia tergolong pada kategori tidak sustain tetapi affordable. Untuk meningkatkan tingkat eko efisiensi bisa dilakukan dengan cara menaikkan harga jual, mengurangi biaya produksi atau menciptakan produksi bersih yang bisa dilakukan dengan menggunakan bahan pewarna alternatif (pewarna alami) dan menerapkan strategi end of life melalui penerapan teknologi tepat guna pencelupan kain batik pada proses pewarnaan.

\section{UCAPAN TERIMAKASIH (Bila ada)}

Ucapan terimakasih disampaikan kepada

Direktorat Riset dan Pengabdian Masyarakat, Direktorat Jenderal Penguatan Riset dan Pengembangan, Kementrian Riset, Teknologi dan Pendidikan Tinggi. Kami juga berterimakasih kepada LLDikti Wilayah 7, Pimpinan Universitas Wijaya Putra, dan LPPM Universitas atas kesempatan melaksanakan kegiatan ini.

\section{REFERENSI}

Nurhayati, S. (2016). Strategi penguatan daya saing Usaha Kecil dan Menengah (UKM) batik menghadapi Asean Economic Community (AEC). Jurnal Ekonomi Dan Bisnis, 19(2).

Irjayanti, M., \& Azis, A. M. (2012). Barrier factors and potential solutions for Indonesian SMEs. Procedia Economics and Finance, 4, 3-12.

Suhartini, N. A. M., Muid, A., Ciptomulyono, U., \& Singgih, M. L. (2011). RANCANGAN SISTEM INFORMASI PENGUKURAN GREEN PRODUCTIVITY DAN ENVIRONMENTAL MANAGEMENT ACCOUNTING UNTUK PENGEMBANGAN USAHA KECIL MENENGAH. Prosiding Seminar Nasional Manajemen Teknologi XIII.

Riyanto, O. A. W., Riyadi, S., \& Kusuma, M. I. (2018). Small-Medium Enterprises (SMEs) Batik Tulis in Jetis Village, District of Sidoarjo. Kontribusia (Research Dissemination for Community Development), 1(2), 29-32.

Hindratmo, A., \& Riyanto, O. A. W. (2019). Enhancing Capability of Tanjung Bumi Batik Sales Bangkalan Madura. Kontribusia (Research Dissemination for Community Development), 2(1), 4-8.

Puspitasari, F. D., Harjanti, W., Yulfajar, A., \& Hamdiyah, N. OBSERVATION OF ENVIRONTMENT AND SERVICE QUALITY

$$
\text { Teknologi Tepat Guna }
$$


TO GAIN COMPETITIVE ADVANTAGE IN SMALL MICRO MEDIUM ENTERPRISE (UMKM) BATIK, JEMBER, EAST JAVA.

DESTARI, F., \& HARJANTI, W. (2018).

Competitive Advantages through Entrepreneurship Orientation and Innovation in Creative Batik Industry in Jember District. Editorial Board, 12(6), 345-360. 